\title{
NUESTRO NOMBRE ES COSTA RICA: CONVERGENCIA DE TIPOLOGÍAS TEXTUALES
}

\author{
Aarón Elí Mena Araya \\ Angélica Castro Camacho
}

Recibido: 02/03/2015 Aceptado: 31/05/2015

\begin{abstract}
Resumen
Este artículo recopila las consideraciones de carácter discursivo y expresivo que modelaron las macroestructuras semánticas y las superestructuras esquemáticas manifestadas en los cuatro videos de la iniciativa Nuestro nombre es Costa Rica ${ }^{1}$, implementada por docentes y estudiantes de la Escuela de Ciencias de la Comunicación Colectiva de la Universidad de Costa Rica, en el contexto del proceso electoral celebrado en el 2014. Se hace un énfasis particular en la utilización complementaria de elementos narrativos y argumentativos para llevar a la audiencia la agenda de contenidos elaborada a partir de los objetivos comunicacionales de la iniciativa. Adicionalmente, se realiza un análisis de la manera en que las personas de la audiencia leyeron los mensajes de los productos de la iniciativa.
\end{abstract}

Palabras clave: Nuestro nombre es Costa Rica; comunicación; política; tipología textual; elecciones; participación ciudadanía; propaganda; redes sociales.

\begin{abstract}
This article discusses the discursive and expressive considerations that shaped the sematic macrostructures and schematic superstructures the four videos published by the "Own name is Costa Rica" campaign, implemented by lectores and students of Costa Rica University Collective Communication Sciences Department, in the context of 2014 electoral process. It focuses on the complementary use of narrative and argumentative elements, in order to convey to the audience the content agenda defined by the communicational goals of the campaign.
\end{abstract}

Key words: Our name is Costa Rica; communication; political; text; typology; elections; participation citizens; propaganda; social networks.

\section{Introducción: la coyuntura de la campaña electoral}

En junio de 2013 la intención de voto en Costa Rica, de frente a las elecciones de febrero de 2014, era convulsa y volátil. Después de la segunda administración de Óscar Arias Sánchez (2006-2010), el Partido Liberación Nacional (PLN) había logrado extender su gestión a un segundo periodo, esta vez con la primer presidente. 
Laura Chinchilla Miranda, quien había derrotado a sus adversarios en febrero de 2010, de manera contundente, con el 46,91\% de los votos.

A pesar del gran apoyo con el que la presidenta Chinchilla llegó a la silla presidencial, durante su mandato la situación política del país adquirió matices de crisis. Durante los cuatro años de la administración Chinchilla se presentó el mayor número de protestas sociales de los últimos 17 años. Sindicatos, grupos ambientalistas, motociclistas, miembros de la comunidad LGBTI, partidos políticos y demás fuerzas, salían a las calles a hacer denuncias de ineficiencia y corrupción.

El Décimo Octavo Informe del Estado de la Nación reveló que el 2011 fue el año con el mayor número de protestas contra el Gobierno en las últimas cinco administraciones. Las 632 ocasiones en que los ciudadanos se manifestaron contra la gestión del Gobierno fueron superadas únicamente por la administración de José María Figueres Olsen (1994-1998), en la que se contabilizaron 755 movilizaciones (Estado de la Nación, 2012).

El descontento social generalizado coincidió con la controversia generada por el conflicto entre los gobiernos de Costa Rica y Nicaragua, debido a la ocupación temporal de la isla Calero y el dragado del río San Juan por parte de los nicaragüenses, la agudización de la crisis de la Caja Costarricense de Seguro Social (CCSS), el escándalo por el mal manejo de fondos en la construcción de La Trocha en la frontera norte, el debate por la concesión de la ruta San José-San Ramón, el viaje realizado por la presidenta Chinchilla a Perú en un avión vinculado con el narcotráfico, y las irregularidades en un megaproyecto para construir un refinería de petróleo con capital chino.

En 2012 y 2013, Chinchilla fue calificada como la mandataria con menos aceptación popular de toda América Latina, con $13 \%$ y $12 \%$ de aprobación respectivamente (EFE, 2012). Además, el Informe del Estado de la Nación señaló que durante su gobierno la brecha entre ricos y pobres mantuvo en crecimiento sostenido, y el Balance Preliminar de las Economías de América Latina y el Caribe 2013, elaborado por la Comisión Económica para América Latina y el Caribe (Cepal), señaló a Costa Rica como el segundo país con más desempleo en la Región.

La caída en el apoyo de la opinión pública hacia el Gobierno se vio reflejada en una disminución de la confianza y credibilidad de los costarricenses hacia la democracia. El informe Latinobarómetro (2013) determinó que entre el 2009 y el 2013, el apoyo al sistema pasó de un $74 \%$ a un $53 \%$, donde se señala a la corrupción como el principal factor de la caída. Esta opinión se reflejó también en la perspectiva a futuro de los ticos, ya que un $73 \%$ de las personas encuestadas en el estudio consideró que el próximo gobierno no iba a ser capaz de resolver los problemas del país en cinco años.

Así, la campaña electoral encontró a los partidos en una situación problemática, en la que debían enfrentar a un electorado desencantado de la clase política y con un creciente escepticismo hacia la legitimidad del sistema democrático. En septiembre del 2013, una encuesta de Unimer para el diario La Nación señaló como claro ganador 
al candidato del PLN, Johnny Araya Monge, seguido por Rodolfo Hernández de la Unidad Socialcristiana (PUSC) y por Otto Guevara del Movimiento Libertario (ML), en segundo y tercer lugar respectivamente (Murillo, 2013).

Sin embargo, con el paso de los meses la intención de voto evolucionó rápidamente. A pesar de que Araya se mantuvo en primer lugar, la renuncia de Hernández ubicó a Guevara más arriba y coincidió con el crecimiento sostenido del candidato del Partido Frente Amplio, José María Villalta, quien se ubicó en segundo lugar. Más tarde, una encuesta del Centro de Investigación y Estudios Políticos (CIEP), publicada el 10 de diciembre de 2013 por el Semanario Universidad, otorgó a Villalta la segunda posición con un 15,7 \% de la intención de voto, dos puntos abajo del liberacionista, y un sondeo de Unimer para el Grupo Nación lo señaló incluso como primer lugar, con 22,2\%.

No obstante, las perspectivas de los niveles de participación en las elecciones eran desalentadoras. Una encuesta del CIEP, publicada el 18 de septiembre por el Semanario Universidad, reveló que el 74,1 \% de los costarricenses no simpatizaba con ningún partido y vaticinó un $40 \%$ de abstencionismo (CIEP, 2013). De este modo, todos los escenarios apuntaban a una victoria del PLN en primera ronda o a la realización de una segunda ronda entre el verdiblanco y alguno de sus rivales.

En este contexto, docentes y estudiantes de la Escuela de Ciencias de la Comunicación Colectiva de la Universidad de Costa Rica reconocieron la necesidad de expresar audiovisualmente la urgencia de ejercer el sufragio, no solo como un ejercicio de responsabilidad ciudadana, sino también como una forma de pensamiento crítico e informado ante la coyuntura política del país. Así tuvo su génesis la iniciativa Nuestro nombre es Costa Rica, la cual se desarrolló entre diciembre de 2013 y enero de 2014, y se centró en la publicación de videos, fotografías y comentarios en redes sociales.

\section{Las redes sociales en las campañas electorales}

Las elecciones son el aspecto definitorio de la democracia, pues proveen los eventos de mayor intensidad y drama (Buckley y Reidy, 2014). En la última década, las redes sociales se han convertido en un nuevo factor que incide en el desarrollo de estos eventos, dinamizando la interacción entra las personas votantes y los discursos políticos. La campaña presidencial que llevó a Barack Obama a la Casa Blanca en el 2008, sobresale como uno de los primeros procesos electorales en el que las redes sociales, principalmente Facebook, cumplieron un rol central en la estrategia de comunicación de una campaña ampliamente financiada. El nuevo poder de las redes sociales se manifestó nuevamente pocos años después, cuando en el 2010 Facebook también sirvió como medio para la canalización del descontento de la una ciudadanía interconectada, y llevó a las movilizaciones de la primavera árabe (Gómez, 2015).

El proceso electoral de 2014 en Costa Rica se caracterizó por la concatenación de varios eventos inéditos en su historia política. La renuncia de candidatos presidenciales 
tanto en la primera como en la segunda ronda de votaciones, se aunó a la participación activa de la ciudadanía en la discusión de ideas, a través del uso de redes sociales. Durante los últimos meses de 2013 y los primeros meses de 2014, por primera vez fue posible para las organizaciones políticas y medios de comunicación, conocer y monitorear las distintas opiniones de la ciudadanía sobre la propaganda difundida y sobre la cobertura noticiosa.

Este cambio puede interpretarse como un resultado de la forma en que el aumento sostenido en el acceso a los servicios de internet fijo y móvil, ha hecho posible el contacto constante de la población costarricense con las redes sociales y medios informativos digitales. Entre el 2010 y el 2013, el número de suscripciones a los distintos servicios de internet aumentó dramáticamente, pasando de 988376 en el 2010, a más de 2000000 en el 2011, para finalmente superar los 4000000 en diciembre del 2013. Esto significó un incremento del $308 \%$ en el acceso a internet, impulsado principalmente por la popularización de los servicios de internet móvil, cuyas conexiones pasaron del $61 \%$ al $88 \%$ del total durante el mismo periodo (Superintendencia de Telecomunicaciones, 2014).

De este modo, la campaña electoral se caracterizó por una presencia activa y beligerante de la ciudadanía en redes sociales, así como por una disminución relativa del peso ejercido por la propaganda electoral distribuida a través de los medios impresos y de radiodifusión (Araya, 2014). Este detrimento de la contundencia de la propaganda pautada en medios tradicionales se puede reconocer particularmente en la relación entre el dinero gastado y los votos obtenidos por algunos de los partidos políticos en contienda. Por ejemplo, a pesar de que el Partido Movimiento Libertario (derecha) fue el segundo con la mayor inversión en propaganda, al reportar un gasto de 1286000 de colones durante los meses de octubre y noviembre de 2013, obtuvo solamente un 11,3\% de los votos para presidente, y cuatro de los 57 escaños del congreso. En contraste, el Partido Frente Amplio, el cual solo reportó un gasto de 371000 de colones en el mismo periodo, contó con un apoyo mucho mayor en redes sociales, y obtuvo un 17,3\% de los votos para presidente y 9 escaños en el congreso (Tribunal Supremo de Elecciones, 2014).

Si bien las condiciones del proceso electoral 2014 incidieron en una participación mayor del electorado en la construcción de discursos, en relación con lo acontecido en el proceso del 2010, según el periodista Cristian Cambronero, la actividad de las agrupaciones políticas en redes sociales se concentraron en la difusión. De este modo, dichas agrupaciones políticas desatendieron otros ejes estratégicos de la comunicación mediada por nuevas tecnologías, tales como la agrupación, la colaboración y la movilización. Cabe mencionar que fue en este contexto donde algunas iniciativas independientes como Nuestro nombre es Costa Rica buscaron abordar los vacíos dejados por las campañas de los distintos partidos políticos. 
El vertiginoso aumento en el acceso a internet de la ciudadanía no solo incidió en la forma en que esta se apropió de la construcción del discurso durante la campaña electoral, sino que también permitió la aparición de emprendimientos informativos sustentados en la interacción con las personas usuarias. Entre estos sobresalen la iniciativa Ojo al Voto dirigida por la periodista Any Pérez, y la aplicación Rete al Candidato desarrollada por el diario El Financiero, y editada por la periodista Kattia Bermúdez. Mientras la primera realizó una cobertura crítica y exhaustiva de los eventos de la campaña electoral, al incorporar el aporte de gran variedad de sectores, la segunda brindó un espacio para que las personas usuarias pudieran hacer preguntas directamente a los candidatos, y dedicó importantes esfuerzos a investigar la veracidad de lo expresado en sus programas de gobierno y sus declaraciones públicas.

Finalmente, cabe resaltar cómo las redes sociales, al permitir la recolección y sistematización de información sobre el perfil de las personas usuarias (intereses, aficiones, características sociodemográficas, etc.), ofrecen nuevos insumos para la construcción y distribución efectiva de los mensajes de las agencias de comunicación y partidos políticos (Spierings y Jacobs, 2012). Por otra parte, las acciones de las personas usuarias, al compartir y comentar un mensaje, pueden potenciar dramáticamente su alcance, aun cuando dicho mensaje sea construido sin un análisis previo del perfil de quienes lo utilizan. Fue esta posibilidad de convertir a las personas usuarias en multiplicadoras y constructoras de mensajes, la que permitió a la iniciativa Nuestro nombre es Costa Rica tener una incidencia importante, a pesar de contar con un presupuesto de apenas unos cuantos cientos de dólares, y sustentarse en trabajo voluntario.

\section{La incidencia de Nuestro nombre es Costa Rica en la campaña electoral}

La iniciativa Nuestro nombre es Costa Rica fue desarrollada por un grupo de docentes y estudiantes de la Escuela de Ciencias de la Comunicación Colectiva de la Universidad de Costa Rica, entre quienes se incluyen las personas autoras del presente artículo, y consistió en una serie de cuatro videos, distribuidos a través de la red social Youtube, y complementados con la publicación de comentarios y fotografías en la red social Facebook.

La iniciativa obtuvo un importante apoyo de la audiencia, evidenciado en la amplia participación en los espacios en redes sociales y en la predominancia de retroalimentaciones positivas. La página de Facebook de la iniciativa consiguió reunir más de 41000 personas seguidoras para el final de sus actividades, a principios de febrero del 2014. Esta cifra se incrementó hasta 42201 personas, para el 28 de febrero de 2015, a pesar de la inactividad de dicha página.

Asimismo, los videos de la iniciativa registraron un número importante de visualizaciones, generaron una considerable empatía entre la población costarricense, reflejada en la proporción positiva entre los "pulgar arriba" y "pulgar abajo" de cada 
video, y estimularon la discusión de la ciudadanía, lo cual se manifiesta en el número de entradas registrado en el espacio de comentarios de cada video. La tabla 1 recopila las cifras correspondientes a estos tres indicadores de incidencia para el 30 de mayo de 2015.

Tabla 1

INCIDENCIA DE LOS CUATRO VIDEOS DE NUESTRO NOMBRE ES COSTA RICA

\begin{tabular}{lccc}
\hline Nombre del video & $\begin{array}{c}\text { Número } \\
\text { de visualizaciones }\end{array}$ & $\begin{array}{c}\text { Proporción entre } \\
\text { "pulgares arriba" y } \\
\text { "pulgares abajo" }\end{array}$ & $\begin{array}{c}\text { Número de } \\
\text { comentarios }\end{array}$ \\
\hline “Nuestro nombre es Costa Rica” & 196.403 & $95,8 \%-4,2 \%$ & 1,014 \\
“iHagámonos Escuchar!” & 15.837 & $96,4 \%-3,6 \%$ & 97 \\
“La Costa Rica que queremos" & 28.175 & $98,7 \%-2,3 \%$ & 91 \\
“'Sabremos elegir!” & 25.977 & $98,1 \%-2,9 \%$ & 143 \\
\hline
\end{tabular}

Fuente: Elaboración propia a partir de cifras del 30 de mayo del 2015.

Estas cifras denotan una importante incidencia de los videos de la iniciativa en el diálogo protagonizado por la sociedad costarricense durante la campaña electoral, principalmente si se considera la reducida población del país y las limitaciones en el acceso a internet experimentado aun por amplios sectores de la población. Vale resaltar que las publicaciones de la iniciativa y la discusión suscitada a partir de estas, fueron cubiertas en diversos medios informativos escritos de Costa Rica, como La Nación, La Prensa Libre, La República y El Financiero, así como en medios informativos electrónicos, como www.ameliarueda.com, www.teletica.com y crhoy.com.

\section{La estructura de los textos comunicacionales}

Las distintas formas de expresión verbal comparten un rol central en la creación y transmisión de significados dentro de cualquier entorno cultural. Estas expresiones se manifiestan en textos comunicacionales concretos, que si bien deben incorporar elementos de lenguaje verbal, pueden aprovechar simultáneamente elementos visuales y auditivos, e incorporar elementos de expresión no verbal.

La estructura de los textos comunicacionales puede abordarse desde la identificación de su carácter bidimensional: como una macroestructura semántica y como una superestructura esquemática (Avendaño y Perrone, 2009). La primera se manifiesta en el núcleo informativo fundamental del texto, es decir, en el esquema de ideas que da un sentido global y cohesionado a los elementos que lo conforman. De este modo, la macroestructura semántica se puede comprender como el esquema conceptual que 
organiza el contenido de un texto. Vale resaltar que la macroestructura semántica de un texto puede manifestarse no solamente en un tema global, sino también en temas locales que se desarrollan dentro del mismo.

Por otra parte, la superestructura esquemática corresponde al tratamiento brindado al contenido del texto, siguiendo esquemas denominados como tipologías textuales; las cuales se articulan en convenciones sobre la manera de expresar las ideas que conforman un texto. En este sentido, la superestructura esquemática guarda un carácter estrictamente abstracto, y se comprende como una herramienta para la construcción y lectura de los elementos estilísticos de un texto comunicacional, independientemente de su contenido. El diálogo, la narración, la descripción, la exposición, la instrucción y la argumentación pueden ser reconocidas como las tipologías textuales fundamentales.

Cabe mencionar que si bien en la especificidad de todo texto comunicacional, la macroestructura semántica y la superestructura esquemática manifiestan una complementariedad inherente, en el proceso de diseño y construcción de un texto comunicacional es posible representar una misma macroestructura semántica mediante diversas superestructuras esquemáticas. Por ejemplo, un mismo esquema de ideas en torno a alguna problemática social específica, tal como la deserción escolar, puede ser abordado a través de textos comunicativos articulados en distintas tipologías textuales: un cuento (narración), un reportaje (descripción y exposición) o un artículo de opinión (argumentación).

\section{Primer video: “Nuestro Nombre es Costa Rica”}

El 27 de diciembre de 2013, en medio de la tregua dictada por el Tribunal Supremo de Elecciones para la campaña electoral, fue publicado en redes sociales el primer video de la iniciativa, el cual se convirtió en un fenómeno viral en cuestión de horas. Una joven vestida de rojo y azul recorría las provincias de Costa Rica, mientras una voz femenina interpretaba con vehemencia el texto presentado en el recuadro 1. 
Recuadro 1

LOCUCIÓN DEL PRIMER VIDEO

I. Hace 30 años ustedes decidieron que "algunos" importan mucho más que "todos".

II. Cogieron las obras de Mora, Sanabria, Calderón y Figueres, y les arrancaron los ladrillos, uno por uno.

III. Los mismos apellidos: hijos, sobrinos, hermanos. Codos sucios que borran lo que había hecho la mano.

IV. Por décadas amarraron de pies y manos al ICE, a la Caja, a nuestras escuelas y colegios, a nuestros campesinos.

V. Con el veneno del miedo, y promesas que se hacen nada, nos siguen robando nuestro pasado y nuestro futuro.

VI. Mataron al agro de a pocos. Hicieron un país que no puede producir lo que se come, pero riega campos de golf con el agua de sus cantones.

VII. Pusieron todas sus fichas en el turismo, pero sus municipalidades nos heredan ciudades claustrofóbicas, sucias, inseguras.

VIII. Llenaron nuestros campos de pesticidas prohibidos, y nuestras playas de portones cerrados. IX. Nos quitaron primero el tranvía, y luego los trenes. Mientras todos los países ponían rieles nuevos, nos ensuciaron la vida con presas, huecos, platinas y trochas ladronas.

X. Se aliaron con los que chupan votos de la fe, y le dieron voz a la discriminación y a la homofobia.

XI. Hicieron pactos con los que quieren privatizar el agua y destruir el salario mínimo.

XII. Nos aplastaron. Nos borraron. Nos humillaron hasta hacernos creer que no es pobre quien vive con 77 mil colones al mes. ¿Uno de cada cinco? Sabemos que son más.

XIII. Cogieron un país pacífico, de grandes oportunidades, y se las arreglaron para convertirlo en un precipicio, más desigual que México, el Salvador y Venezuela.

XIV. Pueden gastar millones en propaganda ridícula y vacía. Nosotros sí sabremos decir todo lo que ustedes quieren callar.

XV. Pueden tratar de asustarnos de nuevo con su orquesta de fantasmas y marionetas. Ya no dependemos de ustedes para informarnos. Ya no pueden esconderse detrás de una bandera. XVI. Les avisamos: No nos vamos a quedar en la casa. Nuestro nombre es Costa Rica, y vamos a votar, pero por ustedes, nunca más.

Fuente: Elaboración propia.

El primer video denota el contenido y el tono que caracterizaría a los videos de la campaña, en sus dos dimensiones como textos comunicacionales. La primera dimensión de este video, correspondiente a la macroestructura semántica, fue articulada en torno a su objetivo principal dentro del contexto de la campaña electoral: invitar a las personas a ejercer el sufragio desde una perspectiva crítica.

De este modo, el esquema de ideas que conforman dicha macroestructura semántica fue elaborado tomando como premisa central el carácter imperativo del ejercicio del sufragio, para luego plantear una serie de premisas secundarias que fundamentaran 
la premisa central. Las premisas secundarias fueron yuxtapuestas para sugerir una correlación entre ellas, y a partir del conjunto de premisas secundarias se infirió la validez de la premisa central. Se puede afirmar que en la macroestructura semántica del primer video, la premisa central corresponde al tema global, y las premisas secundarias, a los temas locales. La tabla 2 presenta la manera en que las distintas premisas mencionadas se correlacionan para dar forma a la macroestructura semántica del primer video.

Tabla 2

MACROESTRUCTURA SEMÁNTICA DEL PRIMER VIDEO

\begin{tabular}{|c|c|c|c|}
\hline Premisas secundarias & \multicolumn{2}{|c|}{ Relaciones } & Premisa central \\
\hline $\begin{array}{l}\text { 1. La clase política ha abandonado el pro- } \\
\text { yecto socialdemócrata en las últimas déca- } \\
\text { das, debilitando la institucionalidad del } \\
\text { país (estrofas de la I a la IV). }\end{array}$ & \multirow{4}{*}{ 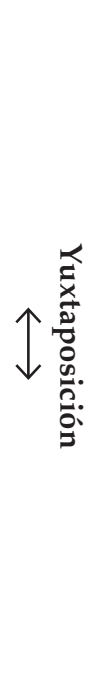 } & \multirow{4}{*}{$\stackrel{\longrightarrow}{\longrightarrow}$} & \multirow{4}{*}{$\begin{array}{l}\text { La ciudadanía debe } \\
\text { ejercer su derecho al } \\
\text { sufragio, buscando una } \\
\text { alternativa diferente a } \\
\text { la clase política que } \\
\text { ha gobernado el país } \\
\text { durante las últimas } \\
\text { décadas (estrofa XVI). }\end{array}$} \\
\hline $\begin{array}{l}\text { 2. La clase política se perpetúa con dema- } \\
\text { gogia y amenazas infundadas (estrofa V). }\end{array}$ & & & \\
\hline $\begin{array}{l}\text { 3. En los últimos gobiernos se han agudi- } \\
\text { zado la corrupción y la desigualdad (estro- } \\
\text { fas de la VI a la XIII). }\end{array}$ & & & \\
\hline $\begin{array}{l}\text { 4. La ciudadanía ya no se encuentra inde- } \\
\text { fensa ante la propaganda de la clase polí- } \\
\text { tica, pues tiene diversas opciones para } \\
\text { informarse (estrofas XIV y XV). }\end{array}$ & & & \\
\hline
\end{tabular}

Fuente: Elaboración propia.

La selección de premisas y el establecimiento de relaciones de inferencia entre ellas son las tareas en las que se sustenta la construcción de argumentos, dirigidos a convencer a un interlocutor individual o colectivo, de la validez de una idea o conjunto de ideas. Asimismo, los argumentos pueden comprenderse como las unidades básicas de la argumentación como tipología textual; por lo tanto, es posible afirmar que el esquema de ideas del primer video se encuentra fuertemente orientado hacia dicha tipología. Esta orientación puede ser reconocida claramente en el contenido expresado a través de los elementos verbales del video: la locución y los datos presentados en pantalla. Así, la segunda dimensión del video como texto, su superestructura esquemática, se enmarca principalmente en la tipología textual de la argumentación. 
Cabe señalar que a pesar de la predominancia de elementos argumentativos, dicha superestructura esquemática también incorpora elementos narrativos. Los textos narrativos se componen estructuralmente de una sucesión lógica de episodios solidarios, es decir, de eventos que guardan entre sí una relación de causa y efecto (Avendaño y Perrone, 2009). Además, la narración suele incorporar, a su vez, elementos de otras tipologías de texto, tales como la descripción y el diálogo.

Entre los elementos de expresión narrativa presentes en el video se encuentra el uso de figuras retóricas, no solamente en el texto de la locución, sino en elementos no verbales, como la imagen en movimiento. En la tabla 3 se recopilan algunas de las figuras retóricas presentes en el texto de la locución.

Tabla 3

FIGURAS RETÓRICAS UTILIZADAS EN LA LOCUCIÓN DEL PRIMER VIDEO

Figura retórica utilizada Estrofa

\begin{tabular}{ll}
\hline Elipsis & “Los mismos apellidos: hijos, sobrinos, hermanos" (estrofa III). \\
\hline Prosopopeya & "Por décadas amarraron de pies y manos al ICE, a la Caja, a \\
& nuestras escuelas y colegios, a nuestros campesinos" (estrofa IV). \\
\hline Concatenación & "Nos aplastaron. Nos borraron. Nos humillaron hasta hacernos \\
& $\begin{array}{l}\text { creer que no es pobre quien vive con } 77 \text { mil colones al mes" } \\
\text { (estrofa XII). }\end{array}$
\end{tabular}

Fuente: Elaboración propia.

Por otra parte, el video también presenta figuras retóricas visuales, expresadas en las imágenes en movimiento. La principal de ellas se manifiesta transversalmente a lo largo de los cuatro videos y corresponde al vestuario y maquillaje del personaje, cuyos colores conforman una alegoría a los colores de la bandera de Costa Rica. Asimismo, para la interpretación del personaje fue seleccionada una persona cuya juventud pudiera ser analizada como una metáfora de los ímpetus de renovación expresados en los mensajes de la iniciativa.

Entre las figuras retóricas visuales presentes de manera particular en el primer video se pueden destacar la sinécdoque, el símbolo, la hipérbole y la metáfora. Cabe señalar que en la mayoría de los casos, estas figuras retóricas se manifiestan en paralelo a figuras homólogas expresadas verbalmente en la locución. La tabla 4 reúne algunas de las figuras retóricas visuales incluidas en el primer video y su explicación en el contexto de lo expresado verbalmente a través de la locución. 
Tabla 4

FIGURAS RETÓRICAS VISUALES UTILIZADAS EN EL PRIMER VIDEO
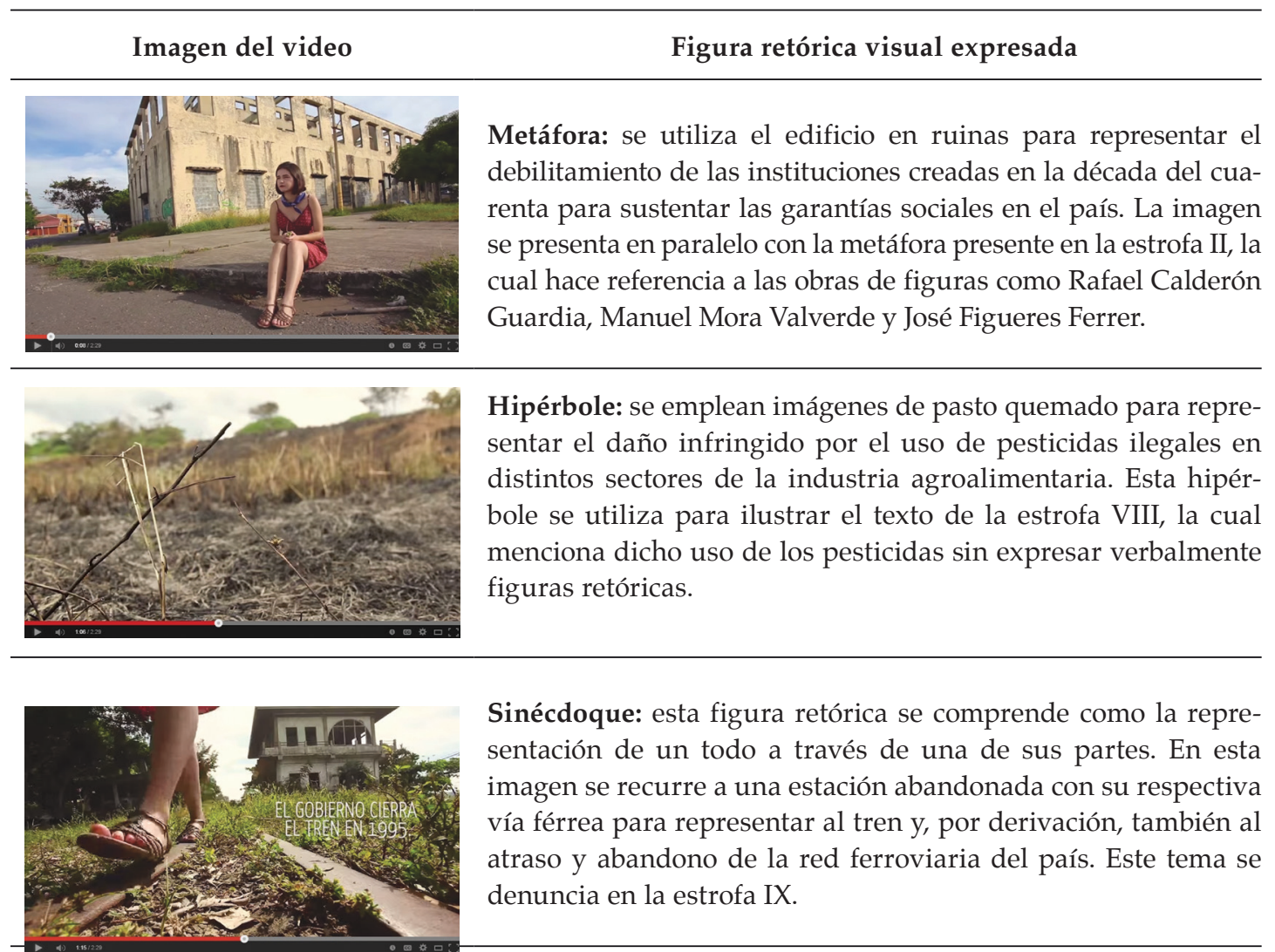

Sinécdoque: esta figura retórica se comprende como la representación de un todo a través de una de sus partes. En esta imagen se recurre a una estación abandonada con su respectiva vía férrea para representar al tren y, por derivación, también al atraso y abandono de la red ferroviaria del país. Este tema se denuncia en la estrofa IX.

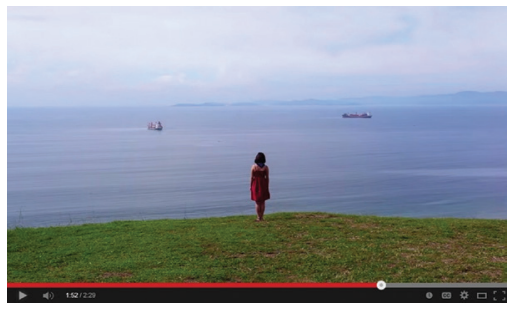

Metáfora: en esta figura retórica se utiliza la imagen del personaje al borde de un precipicio para hacer referencia al peligro que representan los altos niveles de desigualdad socioeconómica en el país. Esta metáfora se complementa con datos del índice GINI del 2013, y se presenta en paralelo con la metáfora incluida en la estrofa XIII.

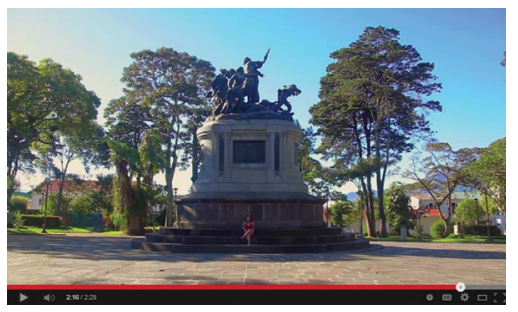

Símbolo: en la parte final del video se emplea como símbolo visual una imagen del monumento nacional, el cual representa la gesta patriótica de 1856. De este modo se incorporó un símbolo conocido por el electorado, y que puede ser relacionado con la invitación a la acción cívica que se realiza en la estrofa XVI.

Fuente: Elaboración propia. 
Como ejemplos adicionales de figuras retóricas visuales planteadas en el video se pueden mencionar las metonimias en las que se presenta al Instituto Costarricense de Electricidad (ICE) y a los campesinos del país, a través de un teléfono público en mal estado y vegetales desechados en una calle josefina (estrofa IV).

Finalmente, cabe señalar que en su dimensión narrativa, las figuras retóricas que hacen referencia a temas locales, se encuentran cohesionadas por una metáfora global manifestada en el personaje caminando de manera decidida por lugares reconocibles de varias provincias del país, hasta llegar al Monumento Nacional. Así, en el video se narra de manera transversal un viaje del personaje para conocer y denunciar la realidad del país.

\section{Segundo video: “Hagámonos escuchar!”}

El segundo video es el más corto de la serie, y fue publicado el 3 de enero de 2014, como una convocatoria a la participación de la ciudadanía en la elaboración de un video, mediante el envío de frases que describieran en 15 palabras o menos uno de los cambios deseados para el futuro de la nación, y de fotografías que representaran a las comunidades del país.

La macroestructura semántica del contenido verbal de este video se enmarca en una invitación a la audiencia a participar mediante una serie de acciones específicas. En congruencia con esto, la superestructura esquemática de dicho contenido verbal puede ubicarse en la tipología textual de la instrucción. Esta instrucción consiste en la selección y presentación de acciones, que conlleven al alcance de un objetivo expuesto explícita o tácitamente. Esta tipología puede ser categorizada como didáctica, debido al uso común en contextos de formación (Avendaño y Perrone, 2009: 62). Por su parte, el video presenta a la audiencia con imperativos categóricos que se concatenan con propuestas de acción ligadas a la materialización de dichos imperativos, y lo hace en el contexto coyuntural de la contienda electoral.

Recuadro 2

LOCUCIÓN DEL SEGUNDO VIDEO

\footnotetext{
I. Nuestra Costa Rica se está moviendo.

II. Se mueve con nuestro trabajo, con nuestras ideas, con nuestras decisiones.

III. Compartamos en una frase uno de los cambios que queremos ver en nuestra Costa Rica. Compartamos también fotos de nuestros campos, pueblos y ciudades.

IV. Con nuestras frases y fotos hagamos un video que resuene con todas nuestras voces y colores.

V. Enviémoslas por correo electrónico a Nuestro nombre es Costa Rica.

VI. ¡Hagámonos escuchar! Nuestro nombre es Costa Rica.
}

Fuente: Elaboración propia. 
Los elementos de la tipología textual de instrucción más claros presentes en el video, pueden ser observados en las estrofas comprendidas entre la III y la VI, pues es en estas donde se brinda la información necesaria para que las personas de la audiencia realicen su aporte a la iniciativa. Es importante resaltar que estos elementos, al apelar a las emociones de la audiencia, al expresar un sentimiento de dinamismo y entusiasmo, también manifiestan una dimensión persuasiva. La figura 1 muestra uno de los elementos que le dan al video su carácter de instrucción.

Figura 1

ELEMENTO DE TIPOLOGÍA TEXTUAL DE INSTRUCCIÓN

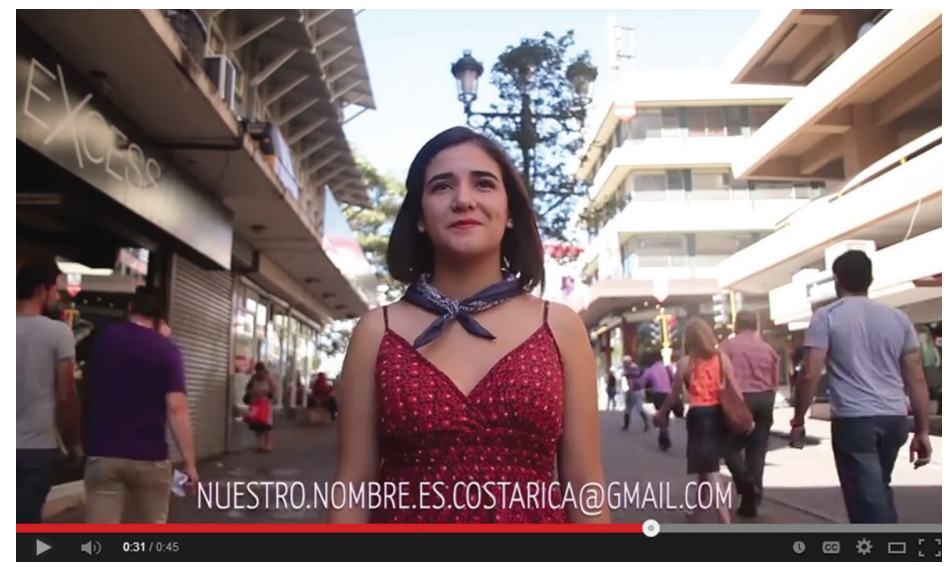

Fuente: Elaboración propia.

Por otra parte, en la dimensión no verbal del video, una vez más pueden identificarse elementos de la tipología textual de la narración, tales como la presentación de una secuencia lineal de acciones protagonizadas por el personaje, y el uso de figuras retóricas visuales. La tabla 5 resume la historia contada a través de las acciones del personaje, la cual puede comprenderse a su vez como un tema local dentro de la superestructura esquemática del video. 
Tabla 5

SECUENCIA NARRATIVA PRESENTE EN EL SEGUNDO VIDEO

\begin{tabular}{l} 
Acciones del personaje \\
\hline $\begin{array}{l}\text { Imagen del video } \\
\text { tras carga una pequeña caja de madera. En el fondo } \\
\text { sobresalen la bandera nacional y la estatua del } \\
\text { héroe nacional Juan Santamaría. Estos dos símbo- } \\
\text { los se utilizan de manera recurrente en el video, } \\
\text { para apelar al sentido patriótico de la audiencia. El } \\
\text { personaje continúa y se sienta, coloca la caja en sus } \\
\text { regazos y la abre. }\end{array}$ \\
\hline
\end{tabular}

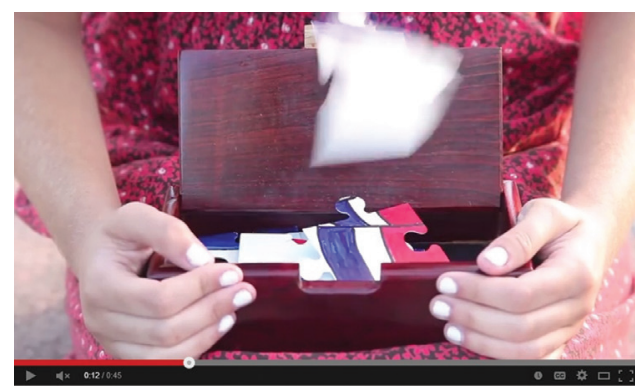

Las piezas de un rompecabezas comienzan a descender dentro de la caja, hasta que esta se encuentra llena. Esta acción se plantea como una metáfora en la que cada pieza del rompecabezas representa una de las fotografías y frases a ser enviadas por la audiencia.

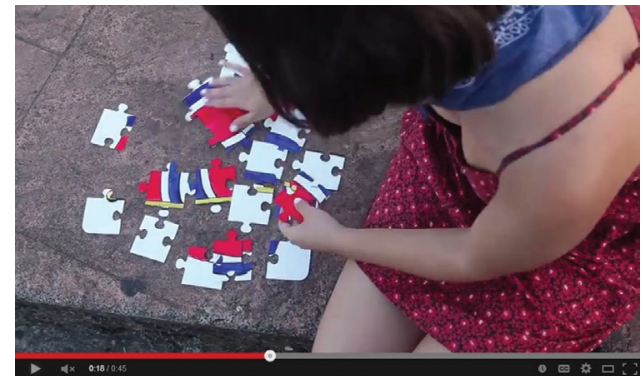

El personaje voltea la caja y comienza a armar el rompecabezas en un timelapse (el cual corresponde a una representación visual de la figura retórica de la elipsis). A medida que el rompecabezas se completa, puede apreciarse que las piezas forman una imagen de la bandera de Costa Rica.

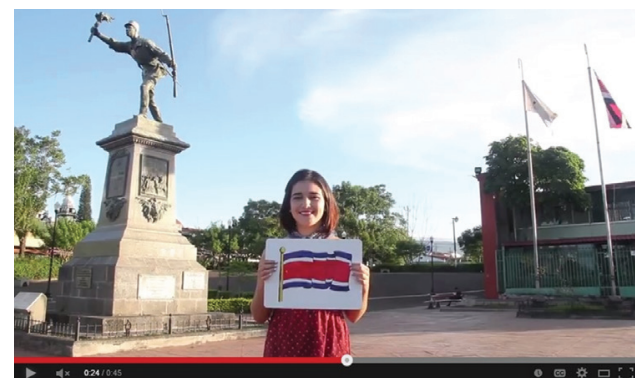

El personaje se muestra de pie, sosteniendo el rompecabezas armado. Aparecen de nuevo en el fondo los símbolos patrios mencionados. La secuencia concluye con el personaje retirándose del parque.

Fuente: Elaboración propia. 
Tras ser completada la secuencia del rompecabezas, el personaje se traslada a sitios emblemáticos de la ciudad de San José, donde permanece inmóvil entre la multitud de los transeúntes. Este es el segundo tema local que conforma el tema global de la superestructura esquemática del video, el cual es aprovechado para canalizar la atención de la audiencia hacia los aspectos operativos que se deben tomar en cuenta para contribuir a la iniciativa.

\section{Tercer video: "La Costa Rica que queremos"}

Con la convocatoria realizada en el segundo video se recibieron más de 300 correos electrónicos con frases y fotografías, entre los que se seleccionaron los elementos a ser incluidos en el video, el cual se publicó el 17 de enero de 2014. De este modo, la macroestructura semántica del video consiste en una recopilación de temas locales, propuestos de forma individual por cada una de las frases aportadas por la audiencia. Estos temas están divididos en dos bloques, y complementados por uno de introducción y otro de conclusión, los cuales hacen referencia a lo que puede ser comprendido como el tema global del video: un llamado de diversas voces de la ciudadanía a cambios que promuevan la justicia social. Los bloques de introducción y conclusión también cumplen la función de mantener el protagonismo del personaje.

Por otro lado, en la superestructura esquemática del video confluyen principalmente elementos de descripción y narración. La descripción consiste en la representación de las características de un objeto, un evento o un proceso. A diferencia de la narración, la descripción no sigue necesariamente una estructura lógica-lineal, por lo que sugiere una relación de causa y efecto.

En este punto cabe señalar que tras obtener la autorización de las personas autoras, la estructura de algunas de las frases fue modificada para mantener la consistencia entre los elementos verbales, presentados de manera sincrónica en la locución del texto desplegado en pantalla.

Además, la unificación en el estilo de las frases dio como resultado nuevamente la aparición de elementos de la tipología textual de la narración: figuras retóricas como la elipsis y la concatenación, las cuales se manifiestan de manera recurrente en gran parte del video. La elipsis corresponde a la eliminación del grupo nominal "una Costa Rica", presentado en las estrofas II y XII, y omitido en las estrofas comprendidas entre la III y la XV. Vale señalar que la organización de estas elipsis responde al hecho de que las estrofas II y XII marcan el inicio de los dos bloques del video que reúnen las frases enviadas por la audiencia. Por otra parte, el pronombre "donde" es utilizado al inicio de las estrofas para producir una concatenación recurrente a lo largo del texto. 
Recuadro 3

LOCUCIÓN DEL TERCER VIDEO

I. Por décadas nos impusieron una Costa Rica de pocas voces y silencios grandes. Pero con nuestro voto sabremos decir alto y claro: ¡Esta es la Costa Rica que queremos!

II. Una Costa Rica con memoria histórica, despierta, protagonista.

III. Con una educación donde nos enseñen a pensar, y no a obedecer.

IV. Sin familias "reales", y sin puestos que vienen por herencia.

V. Donde abunden los árboles en media ciudad.

VI. Dónde quepamos todos con nuestra dignidad intacta.

VII. Que sea ejemplo en carne viva de justicia social e igualdad.

VIII. Donde el turismo beneficie al pueblo y no solo a grandes empresarios.

IX. Donde las empresas privadas respeten nuestros derechos y paguen salarios justos.

$X$. Donde la agricultura sea un trabajo digno y no un medio hacia el empobrecimiento.

XI. Donde podamos caminar sin miedo por las calles.

XII. Una Costa Rica con vivienda para todos y todas.

XIII. Donde todos tengamos alimento sobre la mesa y cultura en el corazón.

XIV. Donde ayuden a las mujeres a lograr su autonomía económica.

XV. Con menos rejas en las casas y más parques en los barrios.

XVI. Donde se respete la maravillosa diversidad de nuestro pueblo.

XVII. Una Costa Rica libre y solidaria, donde cada niño y niña tenga las mismas oportunidades.

XVIII. Estas son nuestras voces y nuestros colores.

XIX. Nuestro nombre es Costa Rica y vamos a votar por el cambio que queremos.

Fuente: Elaboración propia.

Si bien el hilo conductor de los elementos verbales se refleja en los enunciados que describen la Costa Rica anhelada por quienes participaron en la convocatoria, en los elementos no verbales también se manifiesta un hilo conductor construido deliberadamente mediante la selección y organización de secciones de video que presentan al personaje y otras con fotografías enviadas por la audiencia.

El video y las imágenes cuentan la historia de un día, iniciando con el amanecer, y siguiendo hasta el atardecer y la noche. A lo largo del día, nubes van apareciendo, lo que trae una lluvia que luego se dispersa para traer de vuelta al Sol. De este modo, al sugerir una secuencia lineal de eventos en las imágenes, se le suma una dimensión narrativa al video. Adicionalmente, cada fotografía fue animada digitalmente para emular movimiento dentro de ellas.

En la elaboración del video se utilizaron 16 fotografías enviadas por la audiencia, y fragmentos de video que ubican al personaje en tres locaciones distintas: un campo soleado, un campo nublado y un campo de noche. La tabla 6 muestra algunas de las fotografías y capturas de video que constituyen puntos clave en la secuencia narrativa del video. 
Tabla 6

SECUENCIA NARRATIVA PRESENTE EN EL TERCER VIDEO

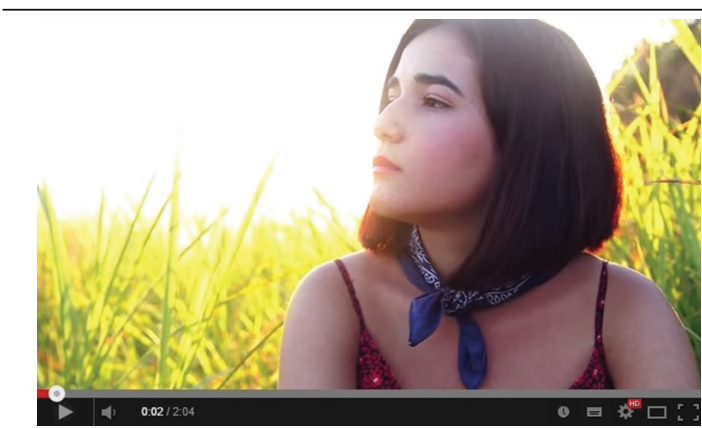

1. El personaje observa el amanecer.

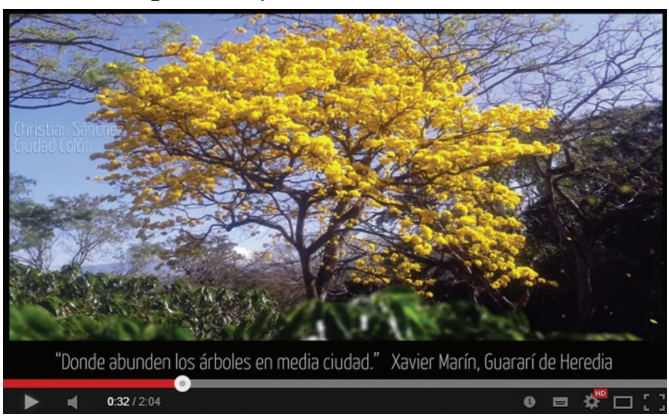

3. La luz del sol se va intensificando.

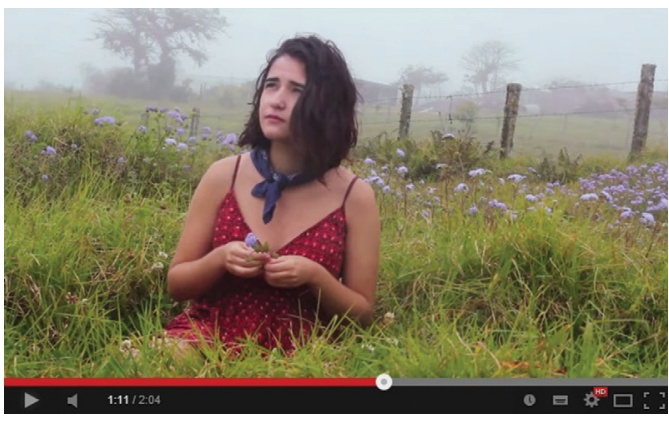

5. El personaje observa las nubes.

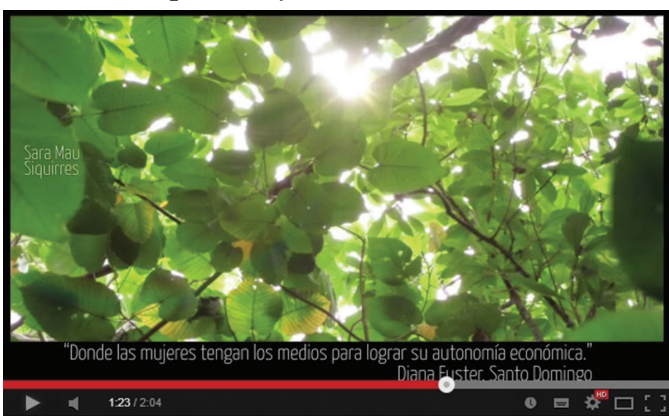

7. La lluvia cesa y el sol se asoma de nuevo.

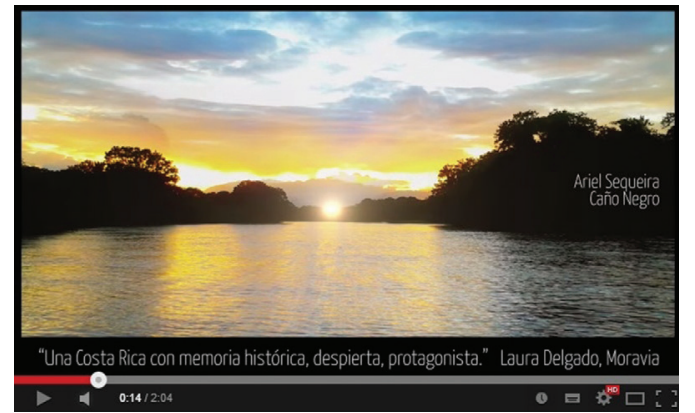

2. Amanece sobre un río.

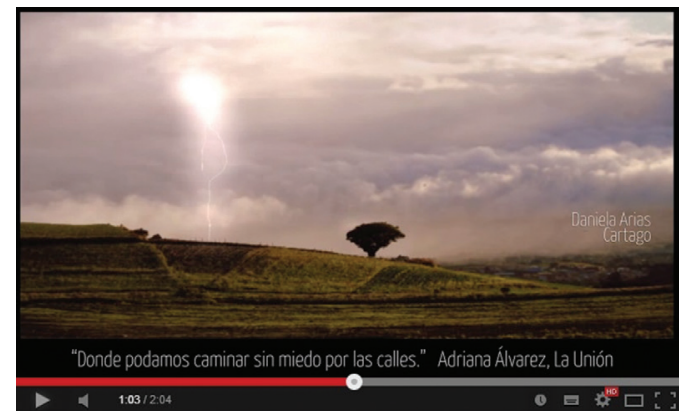

4. Aparecen nubes de lluvia y relámpagos.

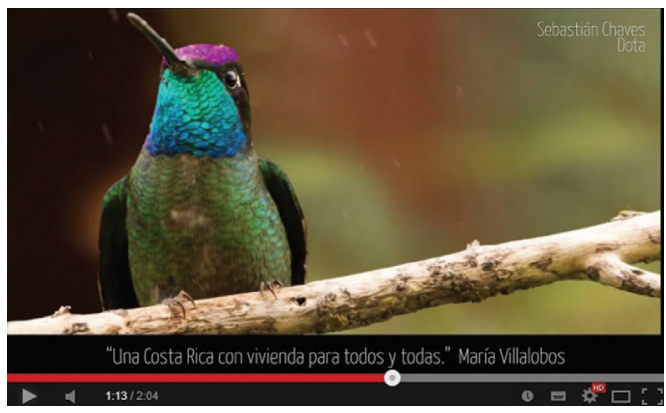

6. La lluvia comienza a caer.

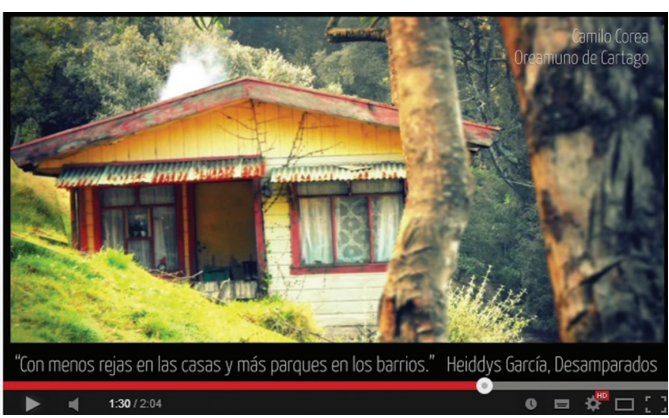

8. Comienza a atardecer. 


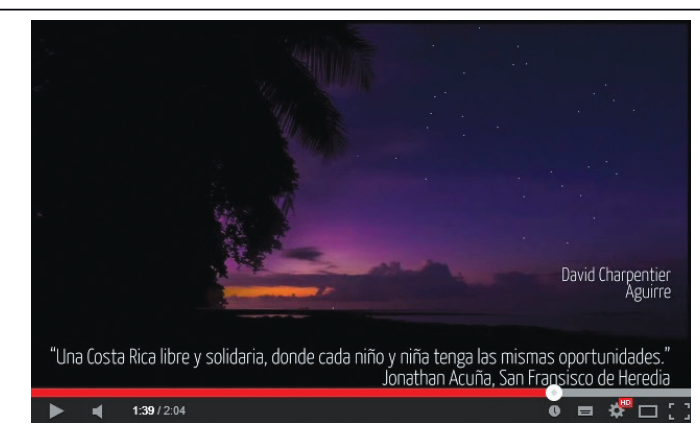

9. Anoche sobre el mar.

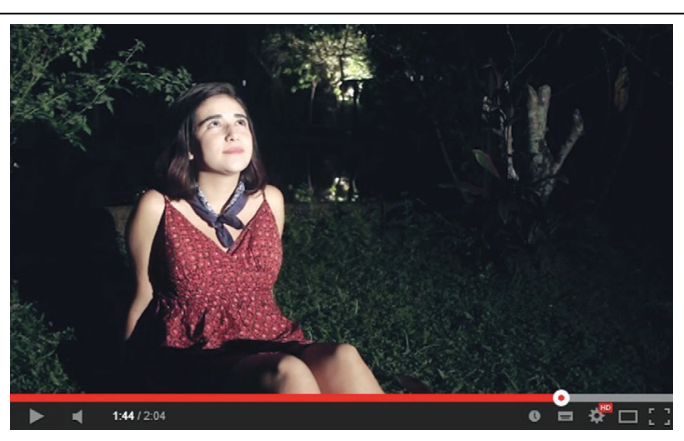

10. El personaje mira las estrellas.

Fuente: Elaboración propia.

Es importante resaltar que la elaboración y publicación del tercer video representó a la vez uno de los principales retos y uno de los principales logros de la iniciativa. El primero consistió en construir un mensaje coherente, tanto en su dimensión verbal como no verbal, al seleccionar y organizar pequeñas piezas de información aportadas por cientos de personas. En este sentido, se puede afirmar que el tercer video tiene un carácter inédito entre las piezas de propaganda publicadas en las campañas políticas del país.

Por otra parte, el entusiasmo mostrado por la audiencia en la respuesta a la convocatoria, y la buena acogida al video manifestada en sus índices de audiencia y comentarios, representan el éxito de la iniciativa en su objetivo de convertirse en un espacio para la participación activa de la ciudadanía.

\section{Cuarto video: "Sabremos elegir"}

El cuarto y último video fue publicado el jueves 30 de enero de 2014, tres días antes de las votaciones de la primera ronda. El video expone la importancia de ejercer el sufragio de manera crítica, reflexionando sobre la trayectoria de los distintos partidos políticos y los méritos individuales de las personas candidatas.

Esta invitación al voto puede comprenderse como el tema central de la macroestructura semántica del video. De manera adicional, es posible identificar la crítica a la equiparación arbitraria de figuras de la política nacional con líderes dictatoriales de otros países de la Región (estrofas de la I a la VI), y las diferencias en la ética y trayectoria de los distintos partidos y personas candidatas (de la estrofa VII a la XIX), como los temas centrales del video. 
Recuadro 4

LOCUCIÓN DEL TERCER VIDEO

I. Por décadas, cada elección ha traído consigo un equipaje grande de miedo. De fantasmas que resucitan cada cuatro años con precisión de reloj.

II. De voces toscas que acusan a cualquier idea distinta, a la idea honesta y solidaria, de ser puerta a desastres y dictaduras.

III. Pero las dictaduras no tienen dueño. No son feudo de izquierdas ni derechas.

IV. Son cátedras de autoritarismo y violencia, de hombres educados en cuarteles, pandillas y trincheras.

V. De esos hombres, que fueron tan familiares también en las Américas.

VI. Que no se nos olvide: Más allá de las ideologías hay hombres y mujeres. Cada uno y cada una con el testimonio de sus acciones. De lo que denuncian, de lo que defienden.

VII. Están los que cada cuatro años gastan miles de millones en propaganda para asegurarnos que todo está perfecto, cada quien en su lugar, y que cualquier cambio nos llevará a un abismo de brujas y espantos.

VIII. Los que nos dan a entender que la pobreza y la desigualdad importan mucho menos que la libertad de unos pocos para desmantelar nuestro país.

IX. Los que una vez cada cuatro años se acusan de corruptos, pero en la Asamblea Legislativa unen votos para regalarse salarios atroces.

X. También están los que trabajan con mucho menos, pero resuenan gigantes, con la voz de tantos y tantas.

XI. Los que saben que la democracia y el clientelismo nunca deben sentarse a la misma mesa.

XII. Los que ven en la corrupción una peste sin excusas, una espina insoportable.

XIII. Los que hicieron caminos nuevos a pasos pequeños, con honestidad y entusiasmo.

XIV. Los que sintieron alacranes en sus banderas, y levantaron otras nuevas, con valentía y experiencia.

XV. Nuestro nombre es Costa Rica, y sabremos elegir.

Fuente: Elaboración propia.

En cuanto a las tipologías textuales presentes en la dimensión verbal del video, se manifiesta una superestructura esquemática similar a la del primer video, en la que predominan elementos de argumentación, complementados por algunos de narración y descripción. El hilo general de la argumentación puede ser equiparado con el tema central mencionado anteriormente, en donde cada uno de los temas locales puede comprenderse como una de las premisas que construyen un único argumento, el cual se articula de la siguiente manera: en ambas partes del espectro político han existido dictaduras (primera premisa), y en Costa Rica hay partidos y personas candidatas de distintas partes del espectro político, 
con vocaciones éticas claramente diferenciadas (segunda premisa), el voto debe ejercerse tomando en cuenta la vocación ética de partidos y personas candidatas, más que los maniqueísmos asociados con una u otra de las partes del espectro político (conclusión). Cabe mencionar, que es en la caracterización de estas personas y organizaciones cuando se utilizan recursos descriptivos.

La locución del video manifiesta además la utilización de recursos narrativos, como metáforas (estrofas I, IV, VIII, XIV, etc.), concatenaciones (estrofa VI), elipsis (estrofas entre la XI y la XIV) y personificaciones (estrofa XI), entre otras figuras retóricas. El uso de las figuras retóricas se extiende a la dimensión visual del video. La tabla 7 recopila algunas de las figuras retóricas visuales presentes en el video.

Tabla 7

FIGURAS RETÓRICAS VISUALES UTILIZADAS EN EL CUARTO VIDEO

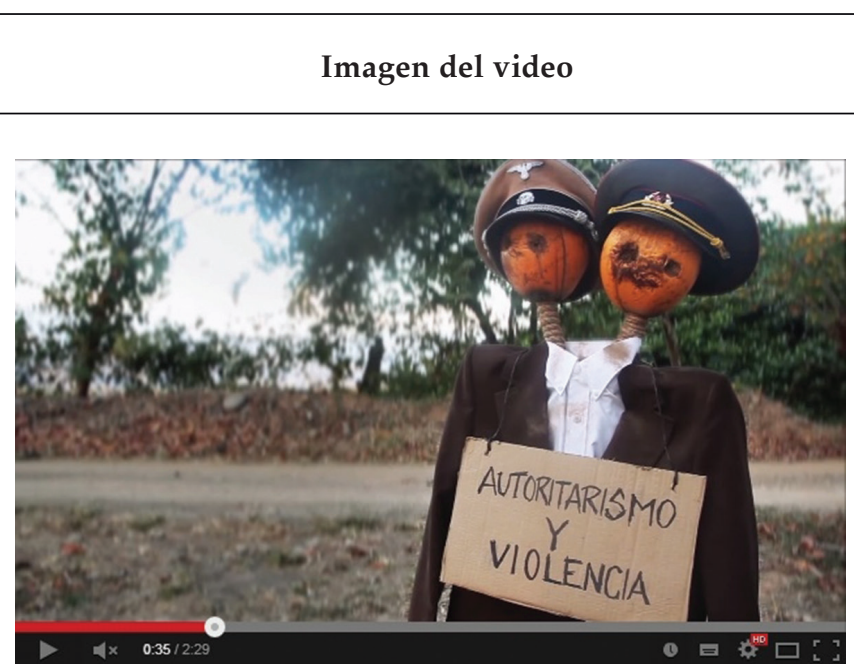

Figura retórica visual expresada

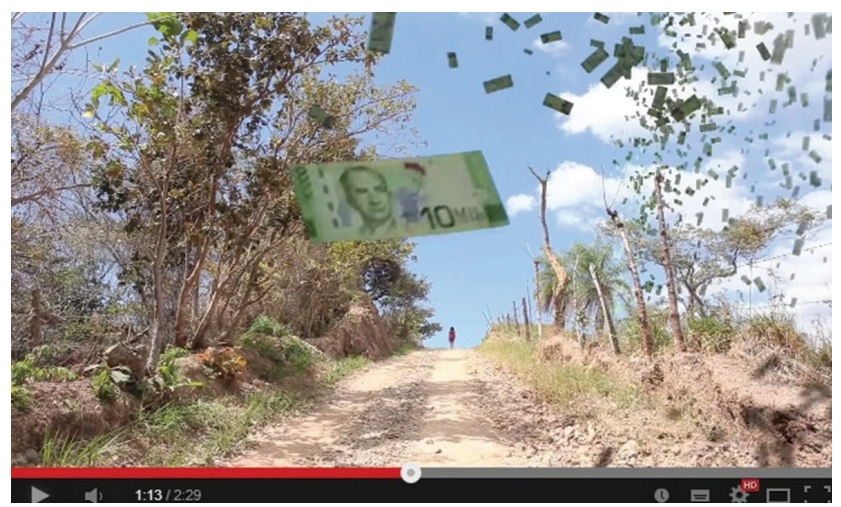

Símbolo: se utiliza un "espantapájaros" bicéfalo, con sombreros militares para representar el autoritarismo y la violencia que caracterizan a los regímenes dictatoriales. Estos sombreros llevan los emblemas de la Unión Soviética y del Partido Nacional Socialista Alemán, símbolos tradicionales de los extremos del espectro político.

Hipérbole: cuando el personaje camina junto a un buitre que se encuentra posado sobre una cerca, este alza vuelo y se convierte en un remolino de billetes, que se elevan y se dispersan por el camino. De esta manera se representa el despilfarro realizado en campañas políticas dirigidas a aterrorizar a la ciudadanía sobre la posibilidad de un cambio en la gestión pública. 


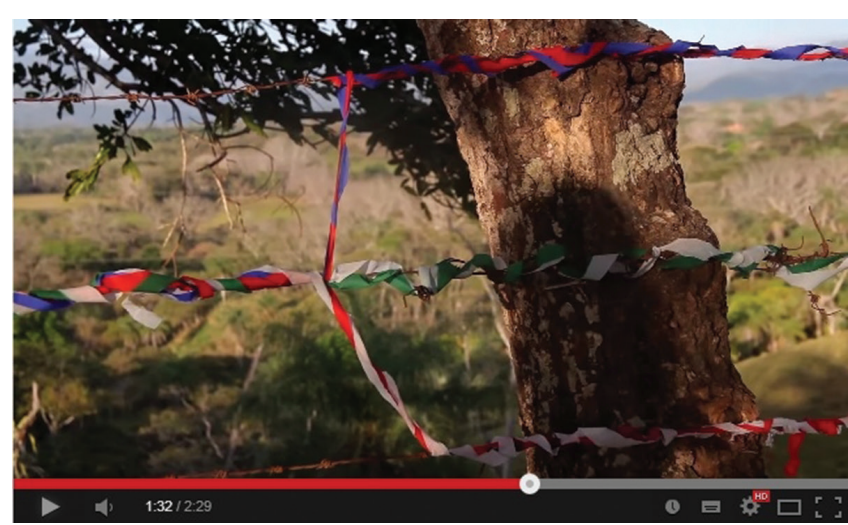

Metáfora: cintas de papel con los colores de tres partidos políticos (Liberación Nacional, Unidad Social Cristiana y Movimiento Libertario) confluyen en una sola bandera, como una metáfora de su afinidad en la gestión legislativa. La sombra del personaje se desplaza de manera apesadumbrada sobre las cintas de papel, representado la apatía hacia los partidos políticos representados.

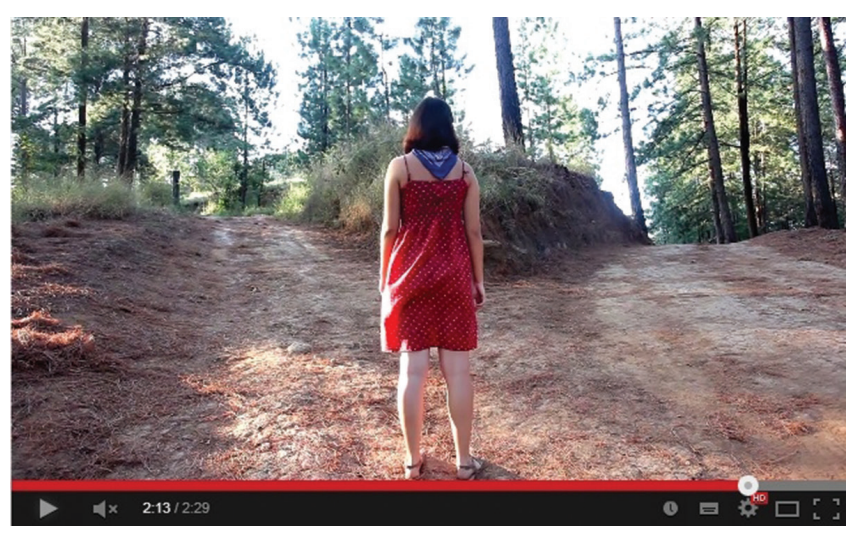

Metáfora: al final del video el personaje llega a una encrucijada, en la cual se le pueden asignar diferentes significados a los caminos. Puede comprenderse como una encrucijada entre los extremos del espectro político, o bien entre la continuidad del bipartidismo y la elección de un nuevo partido para el ejercicio del gobierno.

Fuente: Elaboración propia.

Finalmente, vale resaltar que a lo largo del video se utiliza la alegoría de un camino, donde el personaje "se encuentra" con las figuras retóricas que ilustran la locución. En este sentido, el cuarto video recupera el estilo del primero, en el cual la representación del personaje caminando por los paisajes de Costa Rica se convierte en un vehículo para transmitir argumentos de una manera estilizada y atractiva.

\section{La lectura de los videos por parte de la ciudadanía}

Las publicaciones de la iniciativa generaron diversas reacciones en redes sociales, articuladas principalmente en comentarios de la ciudadanía. En este apartado se recopilan comentarios representativos de los puntos expresados de manera recurrente por personas que interactuaron con las publicaciones de la iniciativa. 
Tal como se describió anteriormente, el primer video está articulado en una premisa central y cuatro secundarias, las cuales son expresadas mediante el uso de diversas figuras retóricas, textuales y visuales. Si bien es imposible conocer el detalle de la forma en que las personas que tuvieron contacto con el video interpretaron dichas premisas y figuras retóricas, la retroalimentación de las publicaciones realizadas, por la iniciativa en Youtube y Facebook, ofrece pistas sobre la lectura de la ciudadanía.

Figura 2

COMENTARIOS POSITIVOS SOBRE EL PRIMER VIDEO

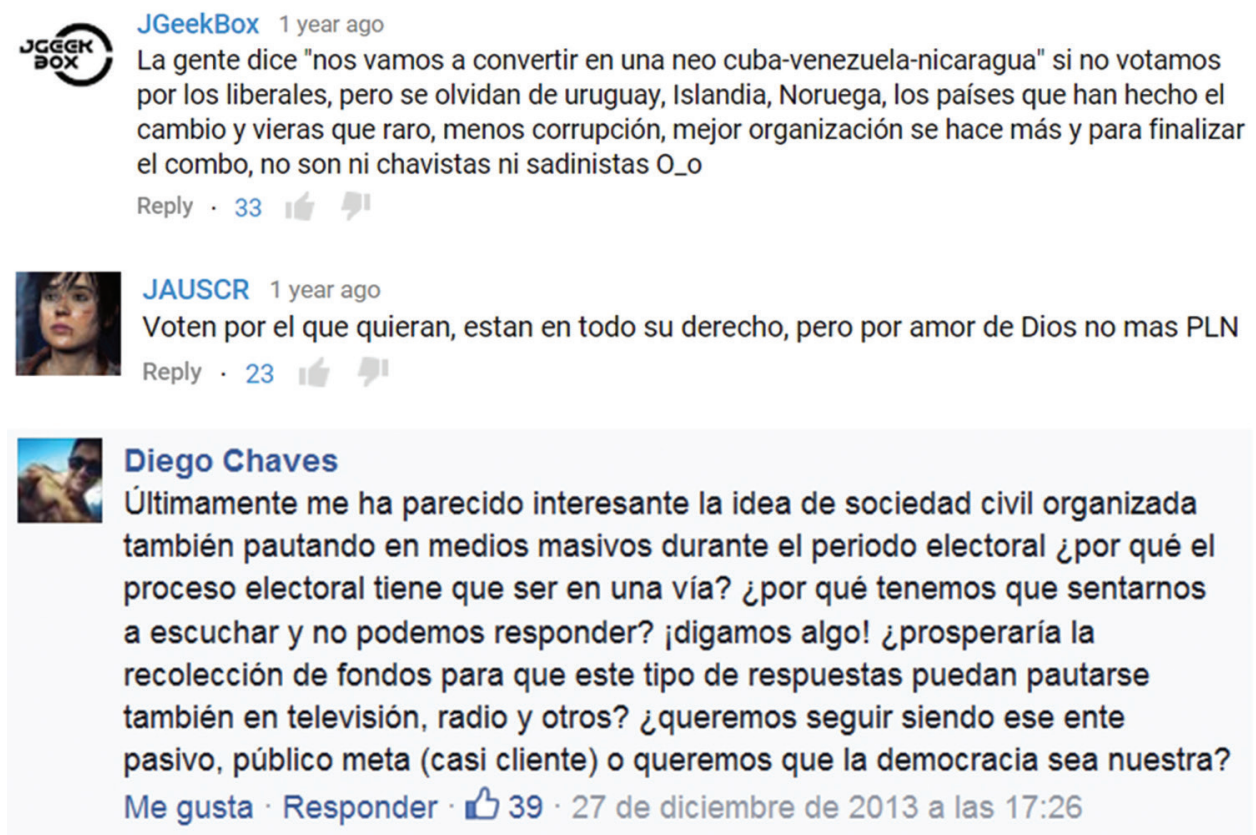

Fuente: Elaboración propia.

Los primeros dos comentarios presentados en la figura 2, los cuales se publicaron en Youtube, no solamente obtuvieron números importantes de "pulgares arriba", sino que hacen referencia implícita a la segunda premisa secundaria y a la premisa central del video: los llamados continuos por parte de los partidos tradicionales a temer cambios en la gestión pública, y la invitación por parte de la iniciativa, a ejercer el sufragio de manera crítica hacia el oficialismo del Partido Liberación Nacional.

El primero de los comentarios hace incluso un cuestionamiento explícito los argumentos esgrimidos por los partidos políticos a la derecha del espectro, acusando a los partidos más cercanos a la izquierda de querer imitar en Costa Rica las políticas implementadas por el presidente Hugo Chávez en Venezuela. Este el caso del tercer 
comentario incluido en la figura 2. Estas referencias denotan que la sección de comentarios del primer video de la iniciativa se convirtió también en un espacio para discutir la generalidad de los mensajes generados en la campaña por las distintas organizaciones políticas.

En la página de Facebook de la iniciativa también se pueden encontrar comentarios en los que, de forma tácita, se reconoce el carácter particular de Nuestro nombre es Costa Rica como un emprendimiento ciudadano, que busca romper la unidireccionalidad observada tradicionalmente en la comunicación política. Es posible afirmar que este comentario hace también referencia implícita a la cuarta premisa secundaria del video, la cual propone que la ciudadanía cuenta con herramientas para informarse y crear sus propios mensajes.

Por otra parte, como se muestra en la figura 3, los comentarios negativos hacia el primer video denotan similitudes entre las lecturas realizadas tanto por quienes se identifican con los mensajes del video, como por las personas con posturas críticas hacia dichos mensajes. Uno de los comentarios contestatarios con más "pulgares arriba" utiliza el término "chancletismo", para ligar la iniciativa con la izquierda política, y descalificar al mismo tiempo sus mensajes. Vale señalar que el costarriqueñismo "chancleta" (un tipo de sandalia) se utiliza para referirse peyorativamente a las personas con afinidad a las ideologías de izquierda.

Por su parte, el segundo comentario cuestiona la selección de los contenidos del primer video, y lo acusa implícitamente de incurrir en una falacia de énfasis, al no hacer referencia a la administración Carazo Odio, caracterizada por una profunda crisis económica y un discurso cercano a las políticas de centro y de izquierda. Así, a pesar de mostrar construcciones retóricas muy diferenciadas, ambos comentarios negativos cuestionan la validez de las ideas expuestas en el video por su consonancia con los discursos de izquierda.

Figura 3

COMENTARIOS NEGATIVOS SOBRE EL PRIMER VIDEO

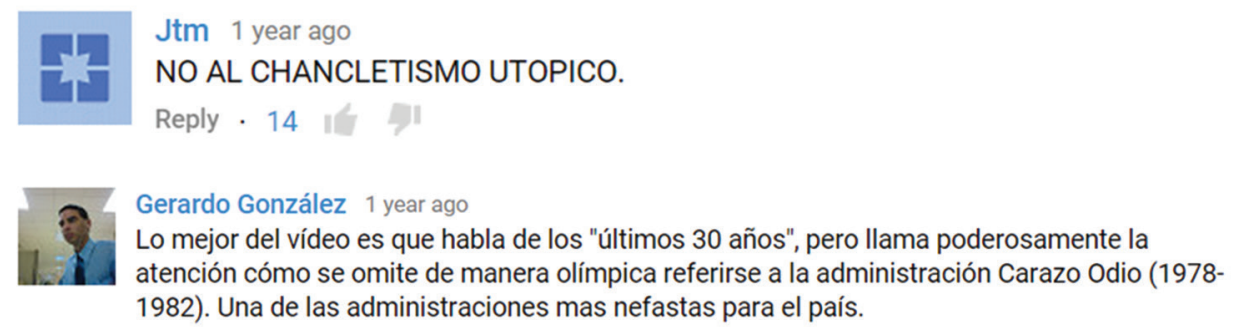

Fuente: Elaboración propia. 
Es importante mencionar que si bien en el primer video no se discuten asociaciones ideológicas o partidarias, la retroalimentación de la ciudadanía denota que las ideas sobre la dicotomía entre la derecha y la izquierda política se manifestaron como una mediación fundamental en la lectura que muchas personas realizaron de los mensajes de dicho video. Este "duelo de ideologías" puede considerarse como un reflejo del tono y los tópicos de discusión que predominaron durante la contienda electoral.

Ahora bien, el segundo video, "Hagámonos escuchar", realiza una invitación a la ciudadanía a contribuir en la construcción conjunta de lo que sería el tercer video, enviando fotografías y frases sobre los cambios deseados para el país. Entre las retroalimentaciones positivas a este video, se pueden identificar lecturas favorables sobre el carácter e incidencia de la iniciativa. Tal como se muestra en la figura 4, para el segundo video se publicaron comentarios que denotan una apropiación del nombre de la iniciativa como una suerte de grito de guerra para llamar al ejercicio del sufragio desde una visión solidaria, y la anuencia de las personas ciudadanas a participar en la convocatoria realizada.

Figura 4

COMENTARIOS POSITIVOS SOBRE EL SEGUNDO VIDEO

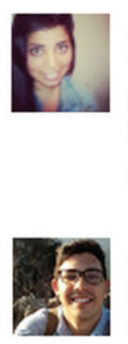

Anita Montero 1 year ago

Todos somos Costa Rica, no importa los nombres y colores con que nos etiquetemos,

siempre seremos Azul-Blanco-Rojo ... Vayamos a votar, no pensando en sí mismo, sino en el bien común... Nuestro nombre es Costa Rica!

Reply $\cdot 9$

Antonio Trejos 1 year ago

Esto es comunicación inteligente. Interactivo e invita a incidir en el mundo real. Claro que me sumo. Felicidades.

Reply $\cdot 6$

Fuente: Elaboración propia.

Por otro lado, los comentarios desfavorables siguieron principalmente el tono de las críticas hechas al primer video, al asociar los mensajes de la iniciativa con ideas de izquierda. Al respecto, en la figura 5 sobresale de manera particular el primer comentario, al imitar la tipología textual predominante en la superestructura esquemática del video, y por interpretar la convocatoria como una expresión de manipulación y autoritarismo. El contraste entre las distintas 
interpretaciones del significado de la convocatoria realizada en el video denota una confluencia de lecturas preferenciales y contestatarias en torno a la macroestructura semántica del mismo.

Figura 5

COMENTARIOS NEGATIVOS SOBRE EL SEGUNDO VIDEO

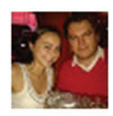

David chacon chacon 1 year ago

De pie, agachados, a un lado, al otro. Hagan lo que les decimos y no piensen.

Reply .

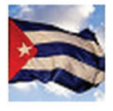

Michel Cespedes 1 year ago

Pffff Costa Rica no es de izquierda. Esos son los deseos de muchos pero será una decepcion

más de los comunistoides fracasados.

Reply · 1

Fuente: Elaboración propia.

Muchos de los comentarios positivos sobre el tercer video, "La Costa Rica que queremos", construido con los aportes de las personas de la audiencia, resaltan el sentido de apropiación de los mensajes de la iniciativa. Estos comentarios, los cuales se pueden apreciar en el primer comentario incluido en la figura 6, manifiestan un tono muy similar a los comentarios positivos predominantes en el segundo video. Vale recalcar que los comentarios del tercer video se caracterizan por un "monólogo" de mensajes favorables, en el que los comentarios críticos sobre la iniciativa se vieron reducidos dramáticamente, para un total de tres de los 91 comentarios publicados.

Debido a que en los comentarios, tanto positivos como negativos, no se hace referencia a la dimensión narrativa del video, no es posible determinar la manera en que esta fue leída por la audiencia, en el segundo y tercer comentario incluidos en la figura 6, se puede apreciar el impacto particular de la idea transmitida en la estrofa XIV, la cual hace referencia a la igualdad de oportunidades para todos los niños y las niñas. Estos comentarios ejemplifican la apropiación espontánea por parte de la ciudadanía de elementos particulares de los videos. 
Figura 6

COMENTARIOS POSITIVOS SOBRE EL TERCER VIDEO

Leo Jiménez Shared on Google+ · 1 year ago

Creo que somos muchos los que compartimos este sentimiento.

Todas las frases y fotografías fueron aportadas por los mismos ciudadanos. Realmente llega esta campaña. Retomemos el rumbo, juntos podemos.

Reply · 14

Lisseth Alemán 1 year ago

Juepuña, sonó "Caña dulce " y se me comenzaron a salir las lágrimas mientras leía los deseos de un pueblo que está harto de la corrupción. Gente, voten por el candidato que prefieran ustedes ya saben quienes no sirven, pero de verdad piensen en el futuro de sus chiquillos y el propio. ¡COSTA RICA! ¡DESPERTÁ YA!

Reply · 6

Geovana Sandoval Cambronero Hermoso, estás son las cosas que le mueven a uno las fibras emocionales para sentir, pensar y actuar de manera responsable por esta Costa Rica, por sus niños y sus jóvenes. Los felicito! Ya no me gusta · Responder · $31 \cdot 17$ de enero de 2014 a las 20:58

Fuente: Elaboración propia.

El cuarto y último video, "Sabremos elegir", hace uso de recursos expresivos similares a los del primero, pues incorpora a su dimensión verbal y no verbal numerosas figuras retóricas. Los primeros comentarios presentados en la figura 7 reflejan la identificación con las ideas transmitidas en algunas de estas figuras retóricas. Adicionalmente, pueden hallarse comentarios que denotan la comprensión de la macroestructura semántica del video, la cual hace una invitación al ejercicio crítico del sufragio, sopesando los atestados éticos individuales de cada persona candidata. 
COMENTARIOS POSITIVOS SOBRE EL CUARTO VIDEO

Sofia Montero Muy lindo eso de que "están los que trabajan con mucho menos pero resuenan gigantes con la voz de tantos y tantas"\#MiVotoEsFrenteAmplio Me gusta $\cdot$ Responder . 130 de enero de 2014 a las 19:05

A. Carol Obando Me encantó lo de las cuerdas entrelazadas entre sí y sus colores de corrupción! (:) Ya no me gusta - Responder · $11 \cdot 31$ de enero de 2014 a las 15:26

Allan Cedeno 1 year ago

No es la izquierda o la derecha, no es el sistema sino las personas que lleguen al poder quienes hacen la diferencia Reply . 6

Fuente: Elaboración propia.

Finalmente, vale resaltar que al igual que en videos anteriores, en el cuarto video el número de comentarios negativos es exiguo, reproduciendo en su mayoría referencias a la dicotomía entre izquierda y derecha. En este sentido, se puede afirmar que si bien los videos de la iniciativa generaron múltiples reacciones, tanto de identificación como de crítica, las discusiones reflejadas en los comentarios abordan de manera limitada la veracidad o idoneidad de las ideas expuestas en los videos, y se centran en la expresión de las afiliaciones ideológicas con las que las personas de la audiencia leyeron los mensajes de la iniciativa.
\end{abstract}

\title{
Conclusión
}

La iniciativa Nuestro nombre es Costa Rica identificó la ausencia de piezas propagandísticas que articularan de manera no partidaria el descontento con las fuerzas políticas tradicionales y el deseo de un cambio en la gestión pública, compartidos por un sector importante del electorado. De este modo, los mensajes de la iniciativa se construyeron tomando como base un número reducido de argumentos que se utilizaron para apelar a una acción específica: el ejercicio de un sufragio crítico.

Estos argumentos fueron llevados a la audiencia, aprovechando recursos verbales y no verbales, literarios y de lenguaje audiovisual. Así, de manera complementaria a la argumentación se utilizaron otras tipologías textuales como la narración, la descripción y la instrucción. 
La dimensión verbal de los mensajes se manifestó en la locución y los textos incluidos en los videos. En esta dimensión se explotaron intensivamente las figuras retóricas, las cuales se encuentran ligadas a las tipologías de la narración y la descripción. Sin embargo, es en la dimensión no verbal de los mensajes, en la imagen fija y en el movimiento, donde se presenta la mayor concentración de elementos narrativos. Estos elementos se manifiestan no solamente en el uso de figuras retóricas visuales, construidas en la interacción del personaje con objetos y lugares, sino también en secuencias narrativas en las que las acciones del personaje o la animación de imágenes fijas, denotan relaciones de causa y efecto, y sentidos de progresión. De esta forma, los videos pueden ser interpretados como breves historias en donde el personaje se desplaza a través de comunidades y eventos de la historia política del país.

Es posible afirmar que uno de los aspectos más particulares de la iniciativa, y posiblemente una de las principales razones por las cuales su alcance no se vio truncado por los recursos limitados con los que se desarrolló, es la convergencia de distintas tipologías textuales para transmitir la macroestructura semántica de sus mensajes.

Las piezas tradicionales de propaganda usualmente definen como su objeto la figura de una persona candidata, o bien la trayectoria histórica o las propuestas de un partido político en particular, y lo expresan haciendo uso de textos expositivos, verbales y visuales. En contraste, Nuestro nombre es Costa Rica estableció como su objeto una suma de anhelos y denuncias, que habían sido expresados de manera recurrente por la ciudadanía durante muchos años.

De esta forma, la iniciativa logró orquestar un discurso preexistente, pero muy fragmentado, mediante el uso de recursos expresivos en una amalgama usualmente ausente en la propaganda política. Esta particularidad incidió en la respuesta de la ciudadanía, la cual desde posturas tanto de simpatía como de crítica, interactuó de forma activa con las publicaciones.

Finalmente, cabe señalar la importancia de desarrollar investigaciones ulteriores sobre la incidencia de los productos de la iniciativa sobre la audiencia, en particular sobre la manera en que las lecturas de las personas de la audiencia contribuyeron al debate en redes sociales, y la posible influencia de este debate en la elección de candidatos por parte de personas indecisas durante la recta final de la campaña electoral.

\section{Nota}

Nuestro Nombre es Costa Rica surgió como parte de las discusiones realizadas en el contexto del curso de Introducción a la Comunicación Audiovisual y Multimedia, impartido en la Escuela de Ciencias de la Comunicación Colectiva de la Universidad de Costa Rica durante la segunda mitad del 2013. La iniciativa contó con la participación directa de doce estudiantes, dos docentes y una fotógrafa profesional. Adicionalmente, dos personas docentes apoyaron a la iniciativa mediante el préstamo de su propio equipo y estudios de grabación. Por lo tanto, el uso de las imágenes tanto del video como de comentarios de este están bajo nuestra autoría. 


\section{Bibliografía}

Araya, Jorge. "Encuesta del CIEP para UNIVERSIDAD: Oferta de candidatos no atrae votantes". Semanario UNIVERSIDAD. 18 de setiembre de 2013.

Araya, Sergio. "Análisis: Una mirada al proceso electoral de Costa Rica". El Financiero. 4 de febrero de 2014.

Avendaño, Fernando y Adriana Perrone. La Didáctica del Texto. Santa Fe, Argentina: Homosapiens, 2009.

Buckley, Fiona y Theresa Reidy. "Tweeting, Tweets And The Political Twitterati: Student Learning And Engagement". American Political Science Association (2014): 1-18.

Centro de Investigación y Estudios Políticos. Informe de la encuesta agosto 2013. San José: 2013. 29 mayo 2015. http://ciep.ucr.ac.cr/index.php/publicaciones/estudios-opinion/Encuestade-Opini\%C3\%B3n-Agosto-2013/.

. Informe de la encuesta noviembre 2013. San José: 2013. 29 mayo 2015. http://ciep. ucr.ac.cr/index.php/publicaciones/estudios-opinion/Informe-de-la-Encuesta-deNoviembre-del-2013/.

Comisión Económica para América Latina y el Caribe. "Costa Rica". Balance Preliminar de las Economías de América Latina y el Caribe 2013. 2013.

Corporación Latinobarómetro. Informe 2013. Santiago: 2013.

EFE. "Laura Chinchilla: con la peor evaluación entre 20 presidentes americanos". CRHoy. com. 23 de setiembre de 2012. http://www.crhoy.com/laura-chinchilla-saca-la-peorevaluacion-de-presidentes-americanos/.

Estado de la Nación. “Capítulo 2: Equidad e integración social”. Décimo octavo informe del Estado de La Nación. San José: 2012. 87-136.

. "Capítulo 5: Fortalecimiento de la Democracia". Décimo octavo informe del Estado de La Nación. San José: 2012. 233-276.

Fernandez, Evelyn. "Bonos de campaña 2014 exceden el monto de la deuda política". El Financiero. 23 de febrero de 2014.<http://www.elfinancierocr.com/economia-y-politica/TSE-PAC-PLN-PUSC-ML-Frente_Amplio-Bonos-deuda_politica_0_469153113. html>.

Gómez, Carmen. "Redes Sociales Y Elecciones". Revista Mexicana De Comunicacion. 24 (2015): 7-24.

Mata, Esteban. “Gobierno enfrentó mayor número de protestas de últimos 17 años”. La Nación. 11 Noviembre de 2012. <http://www.nacion.com/archivo/Gobierno-enfrentonumero-protestas-ultimos_0_1304669653.html>

Murillo, Álvaro. “Nueva encuesta de Unimer: Johnny Araya sostiene su ventaja electoral sin un rival claro". La Nación. 23 de setiembre de 2013. <http://www.nacion.com/nacional/politica/Nueva-Unimer-Johnny-Araya-electoral_0_1368063225.html>

. "Protestas en calles se duplican durante gobierno de Laura Chinchilla". La Nación. 16 de noviembre de 2013. <http://www.nacion.com/nacional/politica/Protestas-callesduplican-gobierno-Chinchilla_0_1378662140.html>

. "Nuestro nombre es Costa Rica". Videoclip en línea. Youtube, 27 de diciembre de 2013. <https://www.youtube.com/watch?v=jG3EedsBZcs>

. “Hagámonos escuchar!: Nuestro nombre es Costa Rica”. Videoclip en línea. Youtube, 3 de enero de 2014. <https://www.youtube.com/watch?v=qBL-lzzbsoA>

. "La Costa Rica que queremos: Nuestro nombre es Costa Rica". Videoclip en línea. Youtube, 17 de enero de 2014. <https://www.youtube.com/watch?v=E2JzUeppIzY> 
. “Sabremos elegir: Nuestro nombre es Costa Rica!”. Videoclip en línea. Youtube, 30 de enero de 2014. <https://www.youtube.com/watch?v=byhgortbieM>

Reis, Carlos. Fundamentos y Técnicas del Análisis Literario. Madrid: Gredos, 1981.

Rodríguez, Víctor. Manual de Redacción. Madrid: PARANINFO, 1991.

Ruiz, Gerardo. "Sólo 53 de cada 100 costarricenses apoyan la democracia". La Nación. 1 de noviembre de 2013. <http://www.nacion.com/nacional/politica/Informe_

Latinobarometro_2013-Costa_Rica-democracia-Gobierno_0_1375662568.html>

Spierings, Niels y Kristof Jacobs. "Getting Personal? The Impact Of Social Media On Preferential Voting". Political Behavior . 36.1 (2014): 215-234.

Superintendencia de Telecomunicaciones. Estadísticas del Sector Telecomunicaciones Estadísticas 2010-2013. San José, Costa Rica: Superintendencia de Telecomunicaciones, 2014. $<$ http://sutel.go.cr/sites/default/files/estadisticassectortelecominforme2010_2013fin al.pdf $>$

Tribunal Supremo de Elecciones. Web. 28 de Febrero de 2014. <http://www.tse.go.cr/ AplicacionVisualizador/datos.aspx>.

Aarón Elí Mena Araya. Costarricense, Máster en Ciencias de la Cultura en la Universidad de Ibraki, Japón. Se desempeña como docente en la Escuela de Ciencias de la Comunicación Colectiva y el Posgrado en Comunicación de la Universidad de Costa Rica, y es además investigador en el Centro de Investigación en Comunicación de la misma institución. Ha publicado sus poemas en el Cuaderno de Poesía Moderna (Japón, 2009), y es autor de diversos artículos académicos sobre temas relacionados con la televisión digital terrestre y la utilización de tecnologías en las escuelas y colegios públicos de Costa Rica, con publicaciones tanto en idioma castellano como en idioma japonés. Director y guionista de Nuestro nombre es Costa Rica.

Contacto: aaron.menaaraya@ucr.ac.cr.

Angélica Castro Camacho. Costarricense, estudiante en las escuelas de Ciencias de la Comunicación Colectiva, y de Filología, Lingüística y Literatura de la Universidad de Costa Rica. Es asistente en investigaciones sobre legislación en Comunicación, en el Centro de Investigación en Comunicación, y de investigaciones sobre manifestaciones culturales afrodescendientes en la cotidianidad del Pacífico Norte costarricense en la Escuela de Ciencias de la Comunicación Colectiva, miembro de la Editorial Estudiantil de la Federación de Estudiantes de la Universidad de Costa Rica y editora de la revista VozUCR. Encargada de tareas de producción y fotografía en Nuestro nombre es Costa Rica.

Contacto: anncastro95@gmail.com. 